\title{
Preliminary Morphological and Phytochemical Evaluation of Momordica cochinchinensis Spreng
}

\section{Halimaton Saadiah Othman*, Nor Adilah Abdul Rahman \& Nor Irdina Mohamed Nizam}

Department of Plant Science, Kulliyyah of Science, International Islamic University Malaysia, Jalan Sultan Ahmad Shah, Bandar Indera Mahkota, 25200 Kuantan, Pahang, Malaysia

*Corresponding Author e-mail: halimatonsaadiah@iium.edu.my

\section{Doi: 10.2478/acmy-2020-0001}

\section{Abstract:}

Momordica cochinchinensis, or Gac fruit belongs to Cucurbitaceae family. Although this species is considered to be native in Southeast Asia especially in Vietnam, Thailand and Laos, it is still contemplated as a rare and new fruit species in Malaysia. Availability of this species is very limited in Malaysia hence, the raw material for researches is also in short supply. Currently, Gac fruit is utilized as traditional food, health supplements, food colouring and juices. Gac fruit was discovered to have high value pharmaceutically and economically as it had been recognized as a rich source of bioactive compounds. On that account, this study aimed to generate preliminary data on the morphological characterisation and phytochemical composition which focused on $\beta$-carotene and lycopene content of Gac fruit aril. This data could be useful for further researches particularly on breeding improvement of Gac fruit. The morphological characterisation was mainly based on both vegetative and reproductive parts of the plant. Both $\beta$-carotene and lycopene content of aril was analysed and estimated using UV-Vis Spectroscopy technique. The aril was extracted using mixed solvent of n-hexane 95\%, ethanol 99.9\% and acetone 99\% with ratio of $2: 1: 1 \mathrm{v} / \mathrm{v} / \mathrm{v}$. Furthermore, morphological data of root, stem, leaf, flower, fruit and seeds were also successfully recorded. Besides that, the $\beta$-carotene and lycopene content obtained were $0.117 \pm 0.011 \mathrm{mg} / \mathrm{g} \mathrm{FW}$ and $0.021 \pm 0.002 \mathrm{mg} / \mathrm{g} \mathrm{FW}$, respectively. Discrepancy in the results might be due to numerous factors like collection sites, level of maturity at harvest, storage and processing conditions, analysis techniques and type of solvent extractors used that might have affected the quality and contents of the carotenoid. Several suggestions for extension of this study had been propounded so that the benefits of this species could be exploited in the best possible ways.

Keywords: Momordica cochinchinensis, morphology, lycopene, $\beta$-carotene, UV-Vis

\subsection{Introduction:}

Momordica cochinchinensis (Lour.) Spreng or commonly known as Gac fruit belongs to the Cucurbitaceae family. Gac fruit was previously widespread throughout Southeast Asia. However, now it is only geographically distributed in certain regions such as Vietnam, Thailand, Malaysia, China, Laos and India. [1]. In Vietnam, it is locally known as Red Gac or Moc Miew Tu, Fak Kao (Thailand), Teruah (Malaysia) Da Ya Mu Bei Zi (China), Khaawz (Laos) and Bhat Kerala (India) [2]. Fruits are big in size (12-17 cm in diameter) and are mostly oval or globose shape-wise. Young fruits are green-coloured and turn into dark red upon maturity [3]. Gac fruit has 3-5 lobed leaves with whitish to ivory flowers which are typically 5-10 cm in length. Flowers grow seasonally, solitary or in bundle. Gac fruit is a perennial dioecious plant. In other words, male and female flowers are borne on separate plants. Often times, hand pollination is required to increase fruit set. Moreover, the development of female flowers is quite slow and production ratio to male flowers is lower. Thus, production of Gac fruit is often low. For growing medium, gac fruit grows best in a well-drained sandy loam soil that is rich in humus or organic matter. For fertilizers, it will depend on the soil type and amount of nutrients already available in the soil [4].

The most useful and nutritious part of Gac fruit is the fruit itself. In Vietnam, locals utilize the Gac aril to make a rice dish called 'xoi gac' [5]. Besides being used as a food ingredient, the Gac seeds are also utilized in traditional Chinese medicine [6]. Gac aril was found to have high levels of $\beta$-carotene and lycopene, $175 \mu \mathrm{g}$ and $802 \mu \mathrm{g}$ per gram of fresh weight respectively [7]. In fact, this is the highest known amount of $\beta$-carotene and lycopene than any known lycopene/carotene- rich fruits and vegetables [8,9]. Indeed, bioactive compounds in Gac fruit have many beneficial effects on human health. Generally, carotenoid consumption could help in combatting vitamin A deficiency in human as $\beta$-carotene is the precursor for Vitamin A production [10]. Apart from that, the Gac aril extract has the anticancer and antimicrobial properties and was found to help reduce the risk of certain life-threatening cancers such as prostate and lung cancer [11].

Despite being widely cultivated and utilized as food and for medicinal purposes in Vietnam, very few studies were available which highlighted on the morphological and phytochemical evaluation of Gac fruit in Malaysia. Since Gac fruit is considered as a newly introduced crop, information on Gac fruit is still lacking which limits the access to useful traits present among the Gac fruit to be further use in breeding and research purposes. Thus, this project is initiated with intention and hope in gathering information and providing preliminary data on morphological and phy tochemical aspect of Gac fruit. Furthermore, in the manner that the potential of the Gac fruit is rousingly known, this species might be developed as one of the promisingly beneficial crops in Malaysia in the near future

\subsection{Materials and Methods}

\subsection{Plant Material Preparation}

Young adult plants of Gac fruit were imported from Thailand and planted in soil medium consisting of topsoil and cocopeat with the ratio of 3: 2. The seedlings were initially kept in nursery under shade of plastic net to protect the plant from overexposure of sunlight. As the plants had progressively grown, the net was removed so that the plants received enough amount of sunlight. Irrigation was twice daily and fertilizer was applied once for every 2 weeks interval. After the fruit had turned into reddish orange and had less firmness, it was considered ripe and was harvested for phytochemical analysis. Data recording for morphological evaluation was also conducted synchronously.

\subsection{Morphological Evaluation}

The morphological description of Gac fruit was mainly based on visual observation. Both vegetative and reproductive parts of the plant were included in the characterisation. For weight, electronic balance was used while length and width were measured with measuring tape. The characteristics included were according to Tran et al. (2016), Tran (2017), Wimalasari (2015) and Wimalasiri et al. (2016) [12,13,14,2].

\subsubsection{Vegetative Part}

The observed vegetative parts were leaf, stem and root. The recorded parameters for leaf were shape, lobe and margin [14]. Besides that, the stem's special characteristic (twining) and root's type were also recorded.

\subsubsection{Reproductive Part}

Parameters taken for the reproductive part include flower, fruit and seeds. For the flower, colour [14], bract, petal and sepalattributeswere recorded. Other parameters included were the seed's shape [13], weight, number and colour [2]. The fruit's shape, spike density [2], mesocarp thickness and colour, aril colour, aril texture and skin colour [13] were also be included in this study.

\subsection{Phytochemical Analysis}

As previously mentioned, Gac fruit is well-known as the source of bioactivecompounds specificallythearilpart. Thus, theidentification ofphytochemical composition in this study focused on lycopene and $\beta$-carotene of the aril.

\subsubsection{Gac Fruit Extraction}

Gac fruit which was reddish orange in colour indicating ripeness were harvested from the plant. Extraction was prepared for 5 replications. The fruit was 
washed with clean tap water then, wiped until dry. After cutting the fruit into halves, the aril was scooped out and separated from their seeds. The fresh aril was collected into a clean beaker and kept in approximately $-20^{\circ} \mathrm{C}$ refrigerator until further use for the extraction process.

The extraction was focused on extracting lycopene and $\beta$-carotene. Hence, the extraction method was performed following the method from Tanongkankit et al. (2018) [15] with modification from the method of Khachik et al. (1992) [16]. Besides that, the procedures were conducted according to the availability of apparatus in the laboratory. The fresh aril was used as the raw material and extracted using the mixture of solvent $n$ hexane $95 \%$, ethanol $99.9 \%$ and acetone $99 \%$ with ratio of $2: 1: 1 \mathrm{v} / \mathrm{v} / \mathrm{v}$ respectively. A quantity of $1 \mathrm{~g}$ of fresh aril was extracted by $60 \mathrm{~mL}$ of the mixed solvent. The beaker's solution was covered with aluminum foil to avoid from exposure of light and air which can cause sample degradation. Then, the solution was stirred using an orbital shaker with the speed of $250 \mathrm{rpm}$ for 30 minutes. After that, the extract was allowed to be filtered through a Whatman No.1 filter paper and washed with $10 \mathrm{~mL}$ of distilled water. The suspension was mixed with $3 \mathrm{~mL}$ of $n$-hexane before centrifuged at 3700 rpm for about 10 minutes. The bioactive compounds; lycopene and $\beta$-carotene content were analysed by using the upper layer of the final product of the extract.

\subsubsection{UV-Vis Spectroscopy Analysis}

The identification and quantification of both lycopene and $\beta$-carotene were conducted using UV-Vis spectroscopy technique by using Perkin Elmer Lambda 35 UV-Vis Spectrometer. The UV detector's absorbance wavelength was set at $507 \mathrm{~nm}$ to analyse lycopene whereas $450 \mathrm{~nm}$ for $\beta$-carotene content. Calibration curve was constructed using various concentrations of standard for both lycopene and $\beta$-carotene which was purchased from Sigma-Aldrich ranging from 0.01 to $0.05 \mathrm{mg} / \mathrm{mL}$ and 0.1 to $0.5 \mathrm{mg} / \mathrm{mL}$, respectively. The stock solution of lycopene and $\beta$-carotene standard was prepared using the formula (1):

Concentration $(\mathrm{mg} / \mathrm{mL})=$ Mass $(\mathrm{mg}) /$ Volume $(\mathrm{mL})$

Then, the standard stock solutions were diluted according to the desired concentrations by using the formula (2):

$\mathrm{Mi} \mathrm{Vi}_{\mathrm{i}}=\mathrm{MfVf}$

$\mathrm{Mi}_{\mathrm{i}}=$ initial concentration $\mathrm{Vi}_{\mathrm{i}}=$ initial volume

$\mathrm{M}_{\mathrm{f}}=$ final concentration $\mathrm{V}_{\mathrm{f}}=$ final volume

The absorbance of extraction of unknown concentrations at both wavelengths; $450 \mathrm{~nm}$ and $507 \mathrm{~nm}$ were recorded and computed into regression equation for calibration curve. Finally, calculated concentration for lycopene and $\beta$-carotene were expressed as mg of lycopene or $\beta$-carotene per one g of fresh sample [15].

\subsection{Results and Discussion}

This species has tuberous root with hard lateral roots (Figure 1). According to Wimalasiri et al. (2015), the tubers can be used as rootstock for propagation purposes [14]. This was also supported by Osman etal.(2017) that mentioned rooted vine cuttings had higher successful chance of propagation than the growing seeds [4].

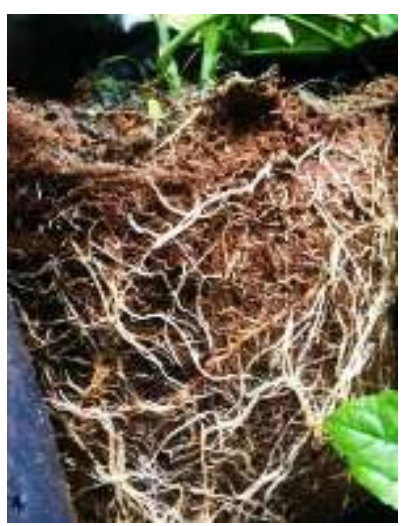

Figure 1: Lateral root of M. cochinchinensis

The simple leaf was dark green in colour, petiolate and arranged alternately on the stem with one leaf per one node attached. It was palmately tri-lobed leaves with dentate margins (Figure 2). However, Wimalasiri et al. (2015) recorded that, M. cochinchinensis leaf of different accessions such as from Tra On, Southern Vietnam which had 5 lobes [14]. The leaf venation was actinodromous where three primary veins diverging radially from one point and also brochidodromous where secondary veins were joined forming loop. The length of the leaf measured from apex to base was $12.5 \mathrm{~cm}$ and was supported by Rahman (2016) who exclaimed that the leaves were 10-12.5 cm [17]

M. cochinchinesis has the common stem characteristic to the Cucurbitaceae family which is climbing or creeping stems (Figure 3) with the help of simple tendrils, modified leaves [18]. The vines could trail up to 2 to $2.5 \mathrm{~m}$ in heights when the plants are fully developed [19]. Besides that, this species had 3 to 4 main stems and other smaller branches which grown from them.

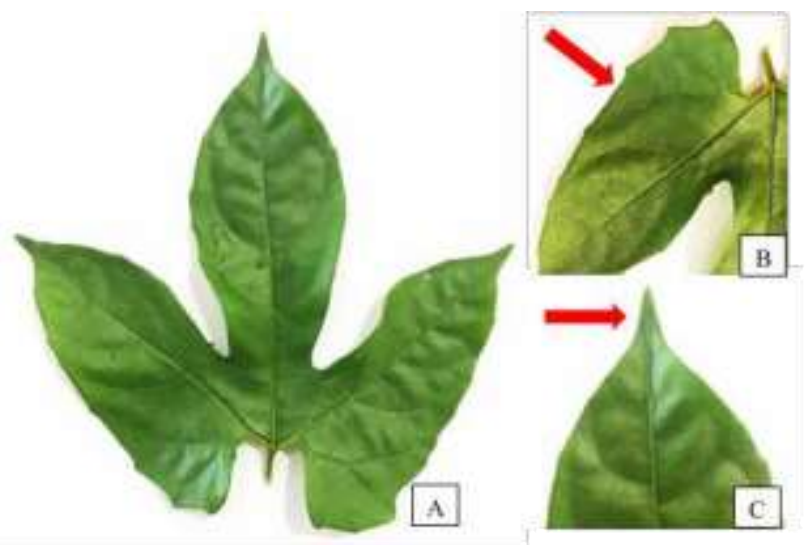


Figure 2: The leaf morphology of M. cochinchinensis (A) Tri-lobed leaf (B) Dentate margin (red arrow) (C) Cuspidate apex (red arrow)
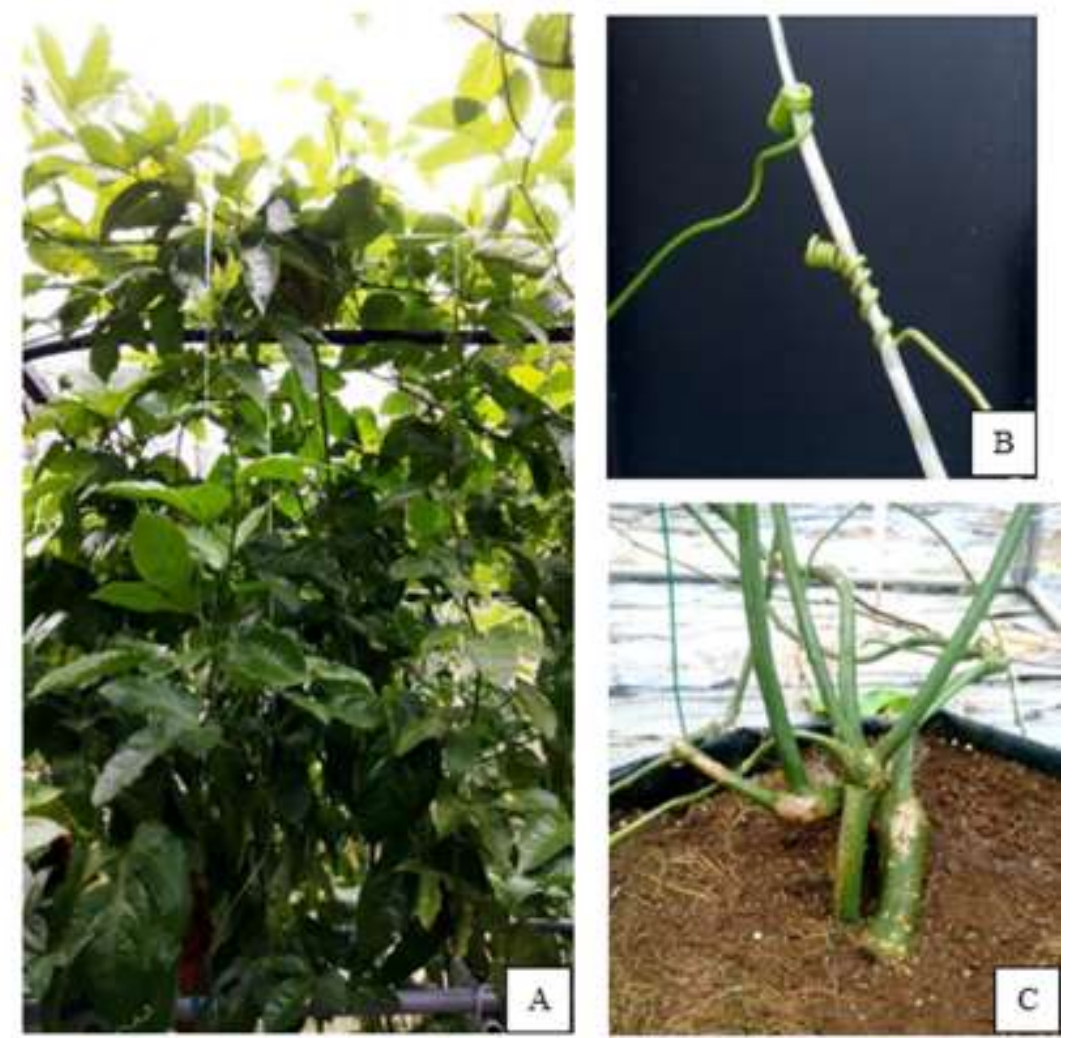

Figure 3: The stem morphology of M. cochinchinesis (A) Climbing vine species (B) Tendrils (C) Main stems

Flower of M. cochinchinensis was yellowish white [14] in colour, dioecious as this species had their staminate and pistillate flowers on different plants, solitary (single flower on its stalk) and actinomorphic (radially symmetrical) with 5 identical petals. The petal was measured 2.5-5 cm [17] and arranged in valvate aestivation, where the petals made contact with each other by their margins but without overlapping. Presence of blackish sepal and bracts as modified leaf on the flower stalk protecting the flower bud. It was also observed that there were trichomes on the bract. Wimalasiri (2015) stated that the bracts of female flower might be small or not existed [14]. Flower presented in Figure 4 was a male flower since there was absence of swollen structure known as ovary which already known to be in female flowers [20].
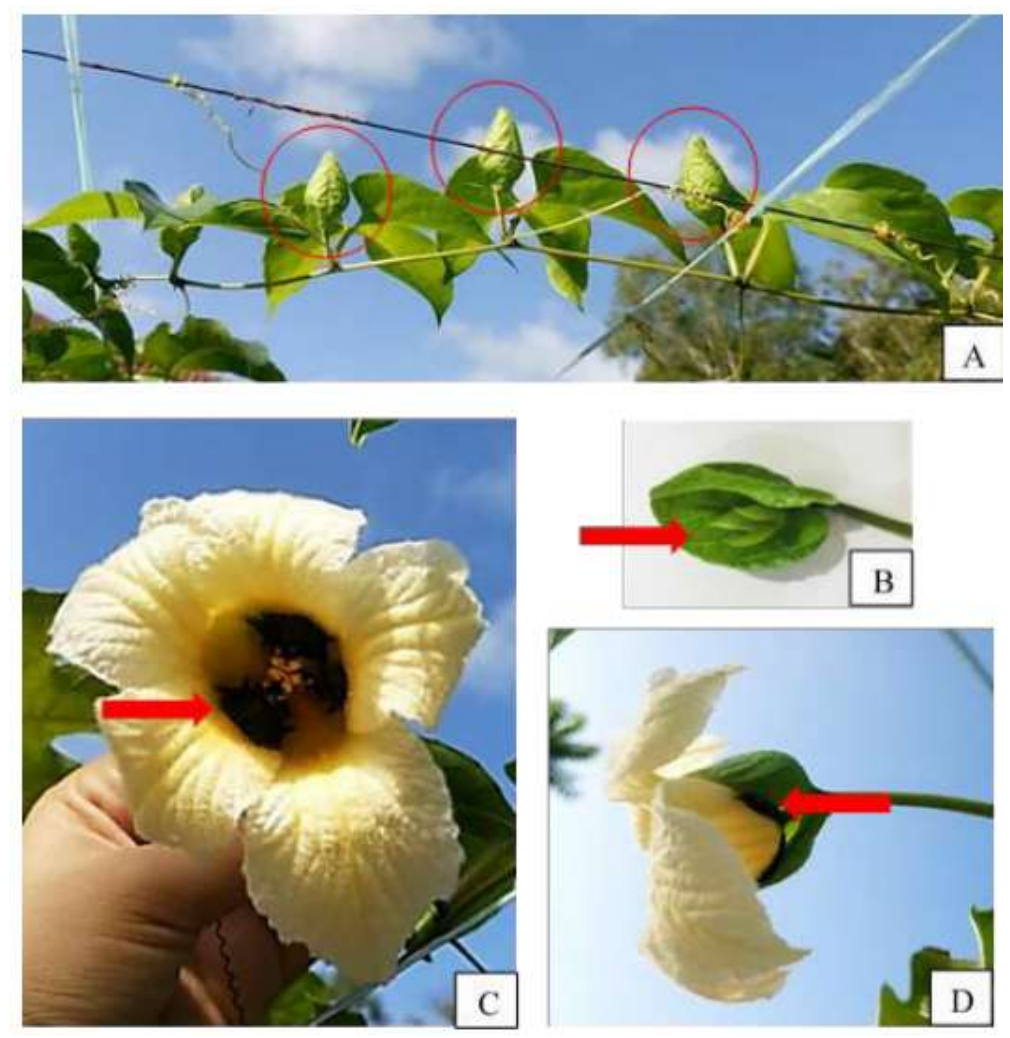

Figure 4: The flower morphology of M. cochinchinensis (A) Flower bracts on vine (red circles) (B) Developing flower (red arrow) inside bract (C) Fullybloomed male flower, androecium (red arrow). (D) Sepals (red arrow)

Measurements for fruit morphology were taken from 3 randomly collected Gac fruit (Figure 5) and the mean value of quantitative results were recorded in Table 1. The fruit's size was measured by its circumference (horizontally and vertically), width and length which were $26.47 \mathrm{~cm}, 28.43 \mathrm{~cm}, 8.33 \mathrm{~cm}$ 
and $10.07 \mathrm{~cm}$, respectively. Furthermore, the weight of the whole fresh fruit was 307.47 ginclusive of the yellowish orange mesocarp that weighted 221.60 $\mathrm{g}$ with thickness of $1.40 \mathrm{~cm}$. Each fruit would bear approximately 29 to 32 seeds with the average total weight of $22.27 \mathrm{~g}$. Since the fruit was generally grown of mesocarp, aril and seeds (Figure 6), aril weight could be estimated by subtracting seeds weight and mesocarp weight from the whole fruit weight which was $63.6 \mathrm{~g}$

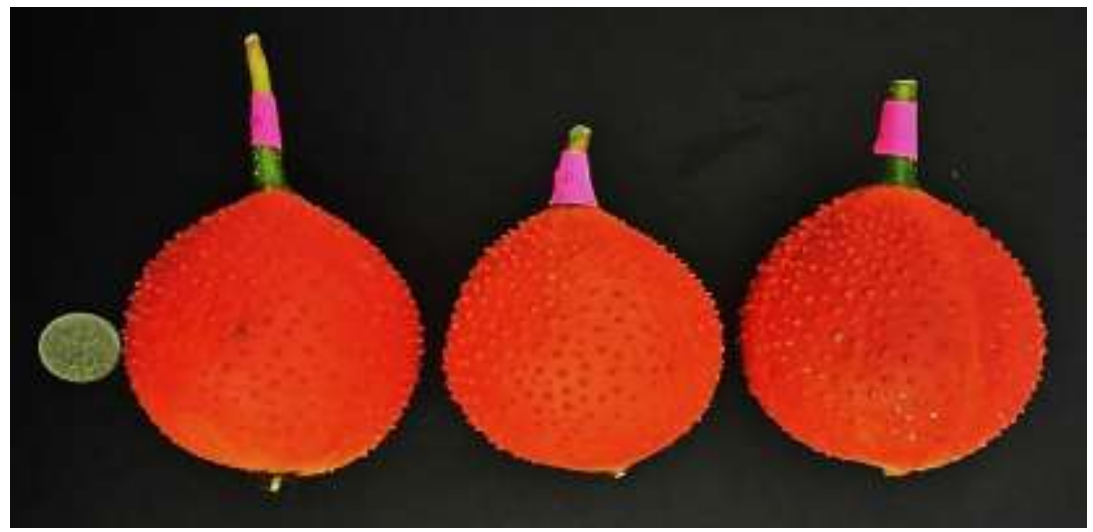

Figure 5: Gac fruits upon maturity

Table 1. The average measurement of fruit's morphology

\begin{tabular}{ll}
\hline Parameters & \multicolumn{1}{c}{ Average measurements } \\
\hline Fruit circumference (horizontal) & $26.47 \pm 0.71 \mathrm{~cm}$ \\
Fruit circumference (vertical) & $28.43 \pm 0.64 \mathrm{~cm}$ \\
Fruit width & $8.33 \pm 0.50 \mathrm{~cm}$ \\
Fruit length & $10.07 \pm 0.42 \mathrm{~cm}$ \\
Fruit weight & $307.47 \pm 28.03 \mathrm{~g}$ \\
Mesocarp thickness & $1.40 \pm 0.27 \mathrm{~cm}$ \\
Mesocarp weight & $221.60 \pm 34.31 \mathrm{~cm}$ \\
Number of seeds & $29-32$ \\
Total seed weight & $22.27 \pm 8.10 \mathrm{~g}$ \\
Fruit circumference (vertical) & $28.43 \pm 0.64 \mathrm{~cm}$ \\
\hline
\end{tabular}

Quantitative results by Osman et al. (2017) were obtained utilising a total of 19 fruits hence, the range values attained were quite wide as for instances the seed number was counted 22 to 67 [4] likewise 7-54 [14] and fruit diameter was measured $27 \mathrm{~cm}$ to $36.4 \mathrm{~cm}$. Furthermore, they described that the fresh fruit weighed $390.8 \mathrm{~g}$ to $1057.8 \mathrm{~g}$, fresh skin weighed $81.9 \mathrm{~g}$ to $220.4 \mathrm{~g}$, fresh aril weighed $45.2 \mathrm{~g}$ to $159.8 \mathrm{~g}$ and fresh seed weighed $45.7 \mathrm{~g}$ to $135.6 \mathrm{~g}$. In comparison, the quantitative measures in this study were about in range with the measurement stated in study by Osman et al. (2017) [4] and Wimalasiri (2015) [14] or even if it was out of range, there was just very little difference.

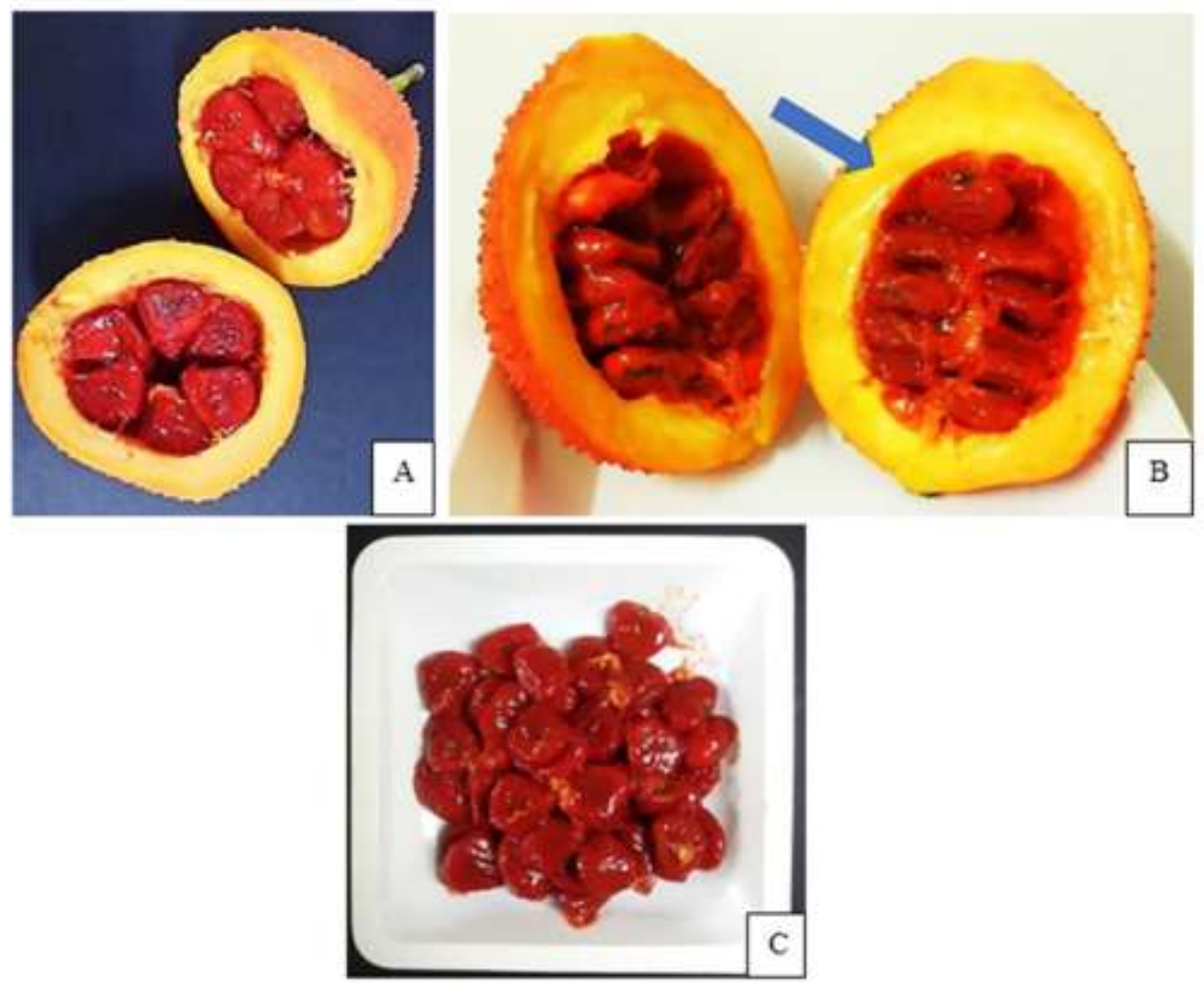

Figure 6: The fruit morphology of M. cochinchinensis (A) Horizontal cross-section of Gac fruit (B) Vertical cross-section of Gac fruit showing mesocarp (blue arrow). (C) Seeds covered with aril 
According to Wimalasiri (2015), shape of Gac fruit from different regions were described as globose, globose-oval, tapered and oval [14]. Furthermore, spike density was categorizedas sparse, medium and dense. Thus, referring to Wimalasiri(2015) proposed indications, it was found out that the shape of the Gac fruit was globose-oval with medium spike density [14]. Furthermore, Gac fruit's type was simple meaning that it derived from single ovary of a single flower.

The placentation or ovule arrangement of Gac fruit was parietal. The colour of the seeds (Figure 7 ) were in variation whether black [21], black brown [4], brown [13] or almost white and was covered by the slick, bright red aril (seed membrane) (Figure 6). Based from observation in this study, the white colour seeds had lesser weight, harder and thinner than the black brown and brown colour seeds. Hence, it was postulated that the white seeds were immature and still not fully developed. Besides that, the shape of the seeds was also irregular and various commonly from broad elliptic to broad ovate.

Figure 8 shows the stage development of Gac fruit from the younger to more mature (from left to right). As the fruit matured and turned ripe, the skin colour and the firmness of the fruit changed. Normally, younger fruits will have green colour and slowly developed orange colour and turned completely reddish orange when fully ripe. Osman et al. (2017) reported that at earlier stage of development, the fruit was in fully green colour until Day 21 and slowly turned into yellow colour until Day 37 [4]. After that, it developed orange colour and finally, the mature fruit turned from orange colour to red colour at around Day 44 to 50 then, ready to be harvested.

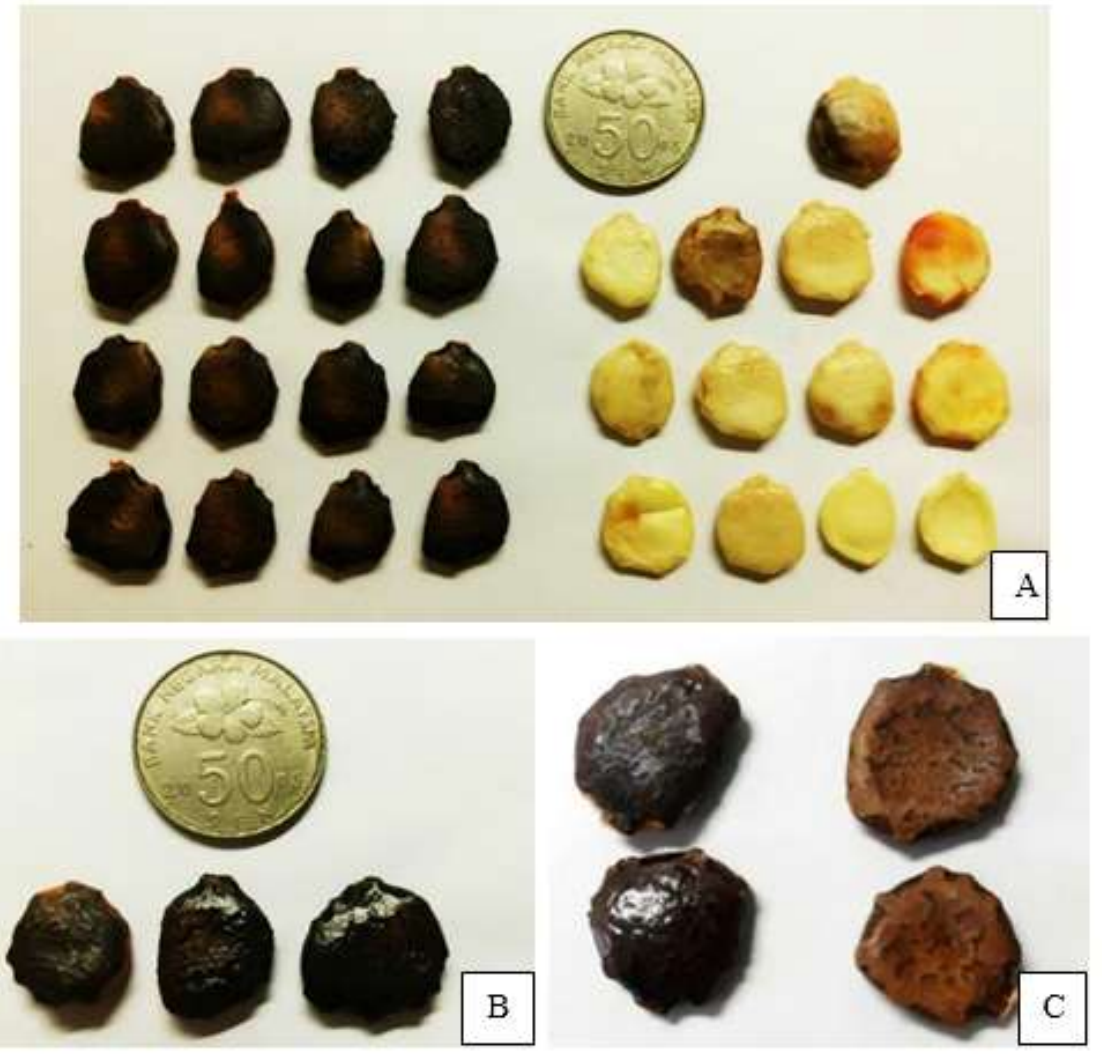

Figure 7: The seed morphology of M. cochinchinensis (A) Difference between mature seed (black brown) and immature seed (white) (B) Shape variation of seeds (B) Colour variation of seeds, (left: black, right: brown)
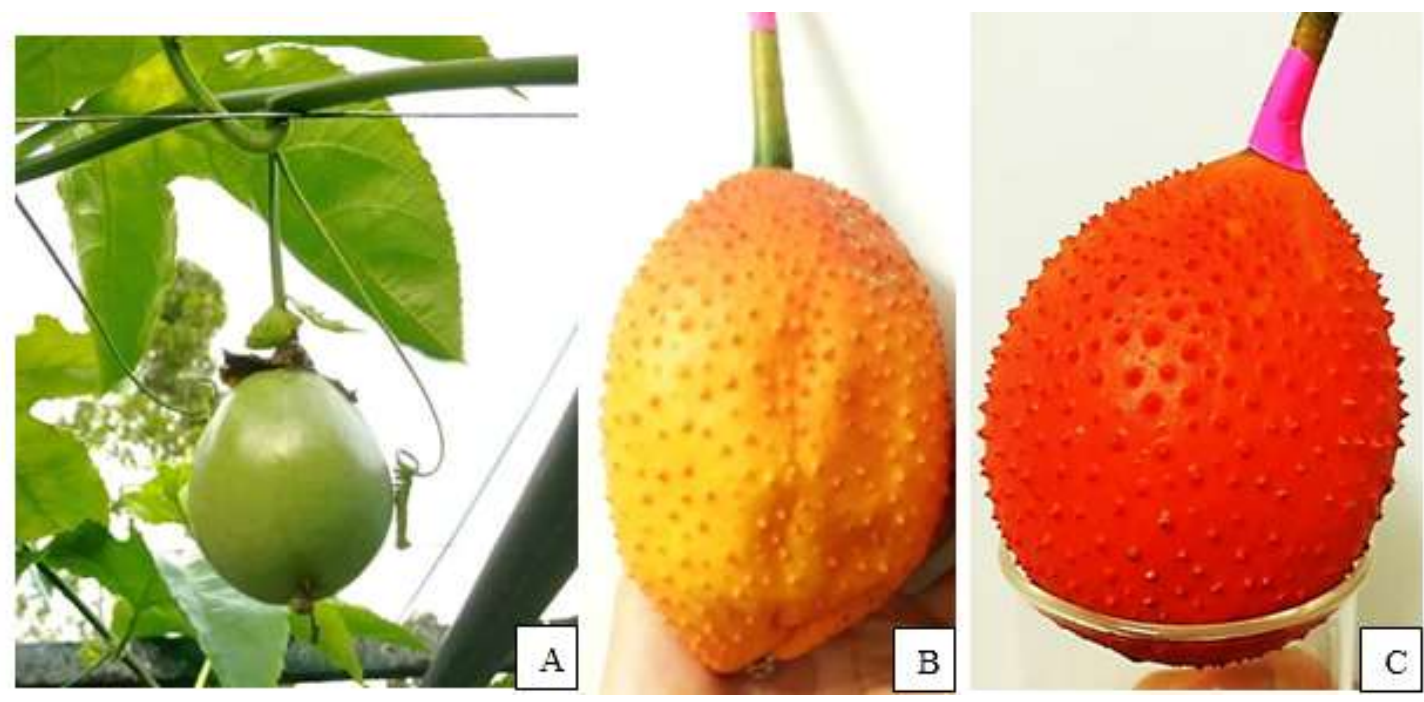

Figure 8: Fruit development (A) Unripe (B) Medium ripe (C) Fully ripe

$\beta$-carotene and lycopene concentration were estimated using UV-Vis Spectrometer. Absorbance (Au) at two wavelengths; $450 \mathrm{~nm}$ and $507 \mathrm{~nm}$ were measured then, the values were computed in the regression equation of standard curve for both $\beta$-carotene and lycopene, respectively. The wavelengths were chosen based on the highest absorption peaks of the compound [22]. 
In order to validate the standard for calibration curve, the correlation coefficient should be greater than 0.9 according to Khachik et al. (1992) which was already achieved for both calibration curve; $\mathrm{R}^{2}=0.9723$ for $\beta$-carotene calibration curve and $\mathrm{R}^{2}=0.9981$ for lycopene calibration curve [16]. Finally, the compound concentration was expressed in unit mg of $\beta$-carotene/lycopene per one gram of fresh weight(FW) sample. In this study, it was found out that Gac fruit aril contained $0.117 \pm 0.011 \mathrm{mg} \beta$-carotene and $0.021 \pm 0.002 \mathrm{mg}$ lycopene for 1 gram of fresh aril sample (Table 2).

Table 2. The average concentration of lycopene and $\beta$-carotene of Gac fruit aril

\begin{tabular}{lr}
\hline Compound & Concent \\
\hline B-carotene & $0.117 \pm 0011$ \\
Lycopene & $0.021 \pm 0.002$
\end{tabular}

$\beta$-carotene content was calculated from the $\beta$-carotene standard curve which was derived from the regression equation $(y=1.829 x+2.2827)$, where $\mathrm{y}$ was the absorbance measured at wavelength $450 \mathrm{~nm}$ and $\mathrm{x}$ represented the $\beta$-carotene concentration in $\mathrm{mg} / \mathrm{mL}$ (Figure 9). Substituting $\mathrm{y}$-value with the mean absorbance value, 2.496 , the mean $\beta$-carotene content was determined to be $0.117 \mathrm{mg} / \mathrm{g} \mathrm{FW}$.

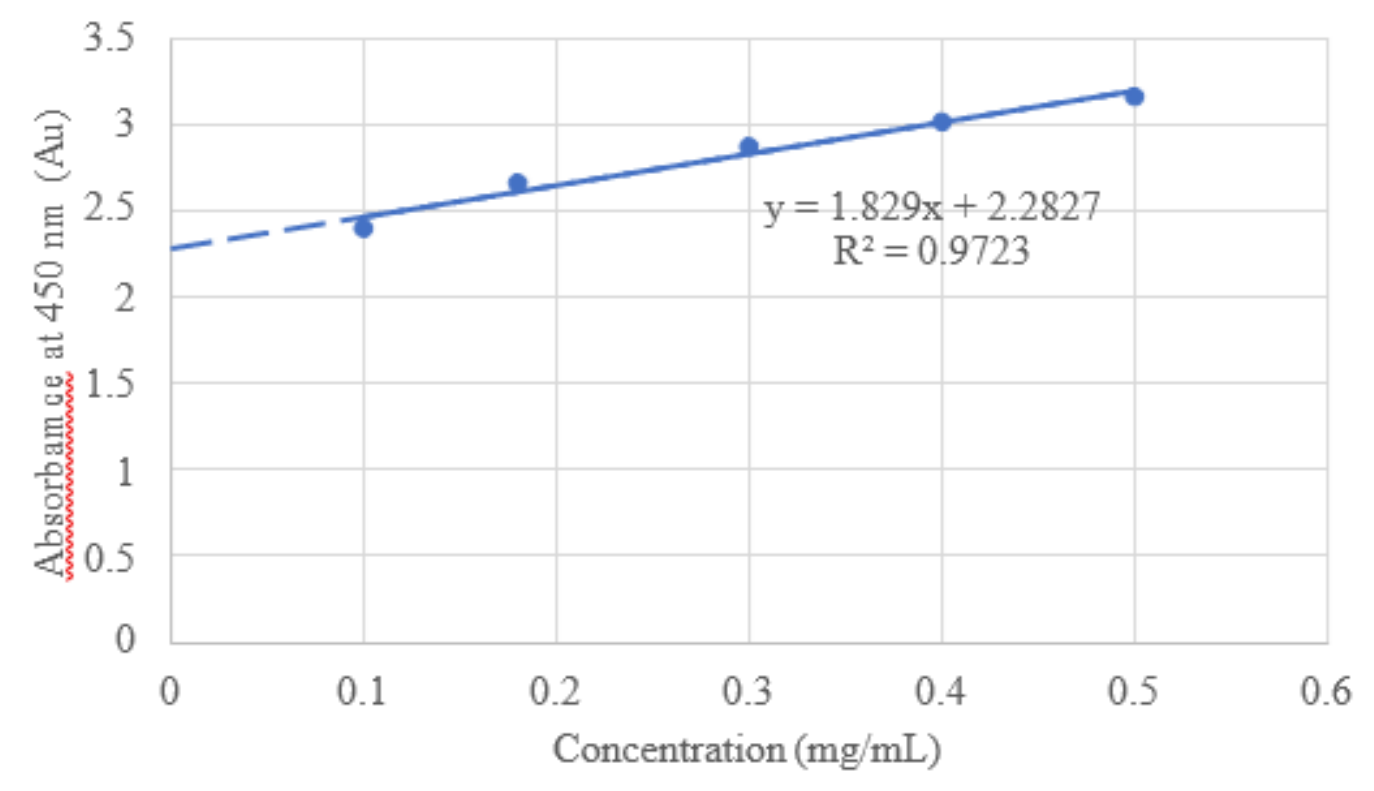

Figure 9: $\beta$-carotene standard curve

The result obtained for $\beta$-carotene concentration in thisstudy was approximately the same with previous research by 0 ki et al. (2002) which was 0.100 $\mathrm{mg} / \mathrm{g}$ FW [23]. Nevertheless, in contrast with research that was conducted by Tanongkankit et al. (2018) which the $\beta$-carotene attained was 0.333 $\mathrm{mg} / \mathrm{g} \mathrm{FW}$ and about three times higher than the obtained value in this study [15]. Besides that, lower concentration recorded was $0.083 \mathrm{mg} / \mathrm{g}$ FW [9] and also higher recorded concentrations were $0.326 \mathrm{mg} / \mathrm{g} \mathrm{FW}$ [10], $0.379 \mathrm{mg} / \mathrm{g} \mathrm{FW} \mathrm{[24]} \mathrm{and} 0.718 \mathrm{mg} / \mathrm{g} \mathrm{FW} \mathrm{[6].}$

Concentration of lycopene was estimated from the regression equation $(y=14.033 x+2.149)$. Calibration curve for lycopene is presented in Figure 10. $y$-value indicated the absorbance measured at $507 \mathrm{~nm}$ while $\mathrm{x}$-value was the concentration of lycopene in $\mathrm{mg} / \mathrm{mL}$. The mean value of lycopene content was $0.021 \mathrm{mg} / \mathrm{g} \mathrm{FW}$ when substituting the mean absorbance value with 2.444 .

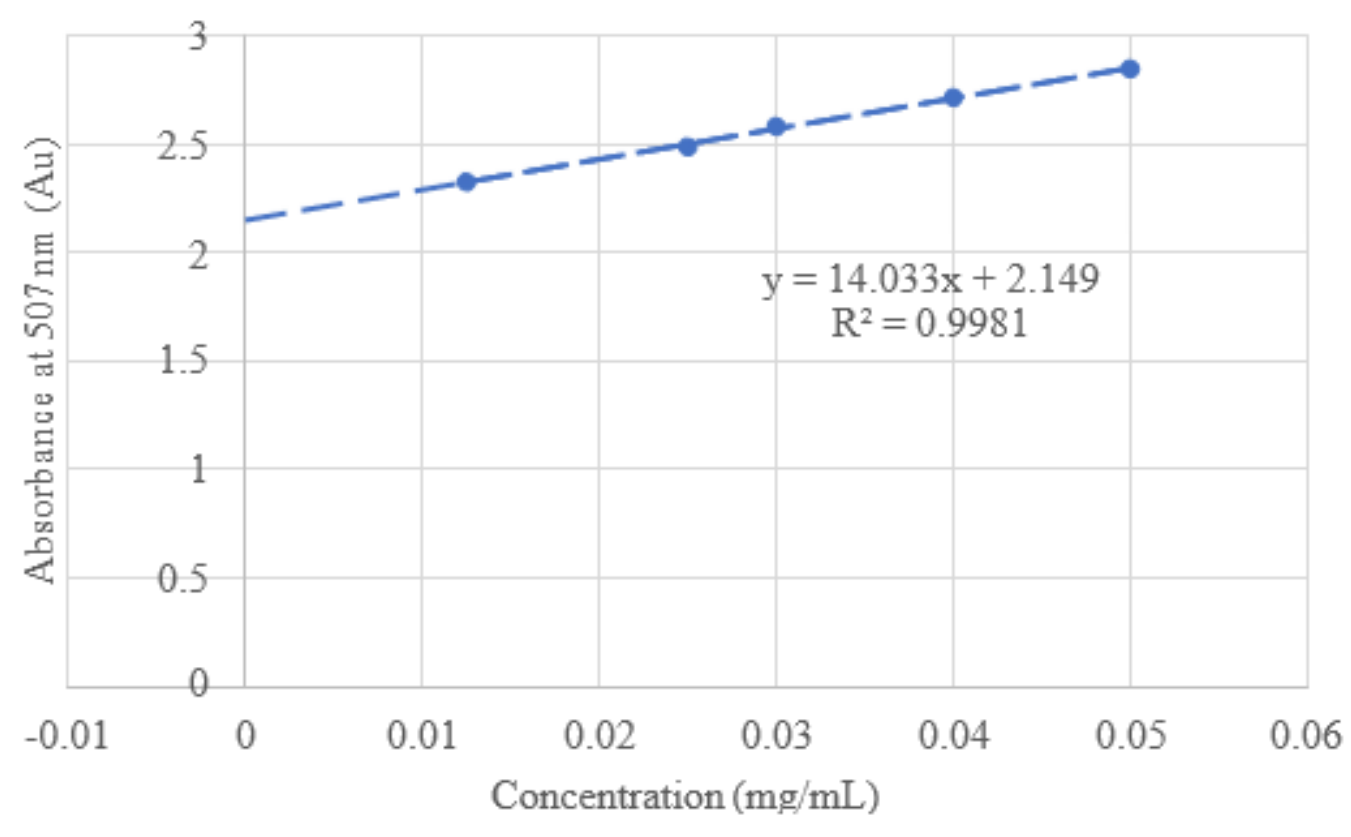

Figure 10: Lycopene calibration curve

Lycopene concentration was always recorded higher than $\beta$-carotene $[6,9,10,1523,24]$ However, the finding from this study was not in parallel with the 
previous studies where lycopene was found to be lower than $\beta$-carotene with $0.021 \mathrm{mg}$ lycopene $/ \mathrm{g} \mathrm{FW}$ and $0.117 \mathrm{mg} \beta$-carotene/g FW. In addition, the attained result was also lower than the recorded concentration from other researches. Previously, lycopene concentrations recorded were 0.435 mg/g FW [15], 0.38 mg/g FW [23], 0.408 mg/g FW [9], 0.454 mg/g FW [10]. 3.728 mg/g FW [24] and 2.227 mg/g FW [6].

Discrepancy in the results could be due to several factors such as the different collection site, level of maturity at harvest, storage and processing conditions, analysis techniques and type of solvent extractor used that might affected the quality and contents of the carotenoid. Determining the maturity and ripeness of Gac fruits might differ according to the harvester. The most common criteria of mature ripe fruit are orange to red skin colour [4] with less firmness of tactile feel [13] when a bit pressure was exerted on it. One might opined that the skin colour has turned orange to red and has lesser firmness while the others might have unlike preferences. A research conducted by Tran et al. (2016) had asserted that stages of maturity defined in weeks after pollination (WAP) which would influence on the phytochemical's attributes inclusive of $\beta$-carotene, lycopene and oil content [12]. Tran et al. (2016) also exclaimed that the fruit quality could be indicated by the skin colour and firmness [12].

Apart from that, storing and processing condition also could affect the physicochemical properties of the fruit. Fruits could be further ripened after harvest coinciding with the presence of ethylene hormone [12]. Normally, the fruit will start to rot after about two weeks after fully ripening. Besides that, even fresh aril stored in approximately $-20^{\circ} \mathrm{C}$ refrigerator, could allow for fungal growth. The best possible ways to store the aril is in $80^{\circ} \mathrm{C}$ freezer. This occurrence could be corresponded to the degradation of carotenoid quality after two weeks of storage [24]. Furthermore, minimum oxygen, light and heat was recommended during processing of the aril samples [20]. After all, high possibility of dissimilar environment of experiments could denote the differences recorded in $\beta$-carotene and lycopene content in this study.

There are numerous available extraction and analysis method to work on with carotenoid content. Obviously, different techniques resulted in different carotenoid concentration values as their concepts are already different in the first place. Most researches were using High Performance Liquid Chromatography (HPLC) technique to analyse the carotenoid contents unlike the technique used in this study which was UV- Vis Spectroscopy. Moreover, the extraction procedures and solvent extractor involved were also distinguishable from another. For instances, fresh Gac fruit aril was extracted using solvent extraction technique mixed solvent of $\mathrm{n}$ - hexane/ethanol/acetone with ratio of 2:1:1, v/v/v [15] whereas Thuat (2010) performed supercritical carbon dioxide fluid extraction [21]

\subsection{Conclusion}

In summary, preliminary study had been conducted on M. cochinchinensis comprising the morphological characterisation and phytochemical evaluation of the species. The morphology of M. cochinchinensis was described by including both vegetative and reproductive parts. Whereas, the aril was subjected to phytochemical analysis to estimate $\beta$-carotene and lycopene content. Understanding the morphological diversity and phytochemical composition of the species is fundamental step towards plant selection for breeding improvement purposes. Besides, it could improvise the strategic germplasm collection for species conservation. Other than that, existing morphological attributes could also help breeders to attain the desired characteristics that are suitable and in high demand for agricultural production especially in the aspects of higher fruit yield. Information regarding the morphology could also improve the cultivation practices.

Contributing to the phytochemical content of the fruit, carotenoids content is known to be predominant. Hence, $\beta$-carotene and lycopene of aril from mature and ripe fruit were analysed. The aril was found containing $0.117 \mathrm{mg} \beta$-carotene/g FW and $0.021 \mathrm{mg}$ lycopene/g FW. However, the finding in this study was not in parallel with previous researches. This might be due to several causes such as different collection sites that have dissimilar agro-climatic, maturity at harvest, storage and processing conditions, analysis techniques and also type of solvent extractor used. Hence, it was suggested to attempt other extraction and analysis method in order to get better and more satisfying results.

\subsection{Acknowledgement}

We would like to acknowledge Kulliyyah of Science, for providing research materials and laboratory facilities and partial research grant (IRAGS18-0460047) funded by Research Management Centre International Islamic University Malaysia through this study period.

\section{References}

[1] T. Behera, K.J. John, L.K. Bharathi, and R. Karuppaiyan. "Momordica. Wild Crop Relatives: Genomic and Breeding Resources", Pp. 217-246, 2011. Doi: 10.1007/978- 3-642-20450-0_10

[2] D. Wimalasiri, T. Piva, S. Urban, and T. Huynh. "Morphological and genetic diversity of Momordica cochinchinenesis (Cucurbitaceae) in Vietnam and Thailand”, Genetic Resources and Crop Evolution, Vol. 63, Pp. 19-33, 2016. Doi: 10.1007/s10722-015-0232-8

[3] L.K. Bharathi, and K.J. John. "Momordica genus in Asia - An Overview", 2013. Retrieved from https://books.google.com.my/books

[4] M. Osman, G. Saleh, Z. Sulaiman, M. Sin. "Gac fruit, a plant genetic resource with high potential”, Transactions of Persatuan Genetik Malaysia, Vol. 7, Pp. 125-128, 2017.

[5] D.P. Toan, H.V. Biet, V.T.T. Hue, H.D. Sang, B.M. Tri, and B.C. Tuyen. "Genetic diversity of Gac [Momordica cochinchinensis (Lour.) Spreng] accessions collected from Mekong delta of Vietnam revealed by RAPD markers", Australian Journal of Crop Science, Vol. 12(12), Pp. 1890-1898, 2017. Doi: 10.21475/ajcs.18.12.12. p1170

[6] B.K. Ishida, C. Turner, M. H. Chapman, T. A. Mckeon. "Fatty Acid and Carotenoid Composition of Gac (Momordica cochinchinensis Spreng) Fruit", Journal of Agricultural and Food Chemistry, Vol. 52(2), Pp. 274-279, 2004. Doi: 10.1021/jf030616i

[7] L.T. Vuong, S.R. Dueker, S.P. Murphy. "Plasma $\beta$-carotene and retinol concentrations of children increase after a 30-d supplementation with the fruit Momordica cochinchinensis", The American Journal of Clinical Nutrition, Vol. 75(5), Pp. 872-879, 2002.

[8] H. Aoki, N.T. Kieu, N. Kuze, K. Tomisaka, N.V. Chuyen. "Carotenoid Pigments in Gac Fruit (Momordica cochinchinensis Spreng)", Bioscience, Biotechnology and Biochemistry, Vol. 66(11), Pp. 2479-2482, 2002. Doi:10.1271/bbb.66.2479.

[9] L.T. Vuong, A.A. Franke, L.J. Custer, S.P. Murphy. "Momordica cochinchinensis Spreng. (Gac) fruit carotenoids reevaluated”, Journal of Food Composition and Analysis, Vol. 19(6), Pp. 664-668, 2006.

[10] T.H. Tran. "Producing carotenoid-rich powder from Gac fruit", 2007.

[11] E. Giovannucci, E.B. Rimm, Y. Liu, M.J. Stampfer, W.C. Willett, "A prospective study of tomato products, lycopene, and prostate cancer risk", Journal of the National Cancer Institute, Vol. 94(5), Pp. 391-398, 2002.

[12] X.T. Tran, S.E. Parks, P.D. Roach, J.B. Golding, and M.H. Nguyen. "Effects of maturity on physicochemical properties of Gac fruit (Momordica cochinchinensis Spreng)", Food Science and Nutrition, Vol. 4(2), Pp. 305-314, 2016. Doi: https://doi.org/10.1002/fsn3.291 
[13] X.T. Tran, S.E. Parks, M.H. Nguyen, P.D. Roach, T.C. Kha. “Changes in physicochemical properties of Gac fruit (Momordica cochinchinensis Spreng.) during storage", Australian Journal of Crop Science, Vol. 11(4), Pp. 447-452, 2017. Doi: https://doi.org/10.21475/ajcs.17.11.04.353

[14] D.C. Wimalasiri, "Genetic diversity, nutritional and biological activity of Momordica cochinchinensis (Cucurbitaceae)", 2015.

[15] Y. Tanongkankit, N. Wichit, N. Chaikan, P. Saehan. "Ultrasonic- assisted extraction of lycopene and $\beta$-carotene from Gac arils", Paper presented at the ISER 148th International Conference, Melbourne, Australia, 2018.

[16] F. Khachik, G.R. Beecher, M.B. Goli, W.R. Lusby. "Separation and quantitation of carotenoids in foods. Methods in Enzymology Carotenoids Part A: Chemistry, Separation, Quantitation and Antioxidation”, Pp. 347-359, 1992. Doi: 10.1016/0076-6879(92)13136-1

[17] A.H.M. Rahman, "Systematic Studies on Cucurbitaceae Family at Rajshahi Division, Bangladesh", Science Publishing Group, Vol. 1(2), Pp. 10-15, 2016. Doi: https://doi.org/10.11648/j.plant.20130102.11

[18] M.G. Ajuru, B.E. Okoli, "The morphological characterisation of the melon species in the family Cucurbitaceae Juss., and their utilization in Nigeria", International Journal of Modern Botany, Vol. 3(2), Pp. 15-19, 2013. Doi: 10.5923/j.ijmb.20130302.01

[19] T. Motis, “Gac: A colourful and health-promoting fruit, 2017. Retrieved from https://www.echocommunity.org/en/resources/ae7b472c-b83d-4786a161- 321f26e88469

[20] S.M.K. Saadedin, Al-Zaidi, I.H. Mohammed, Al-Awadi, S.J. Abdullah. Bioscience Research, Vol. 14(4), Pp. 788-800, 2017.

[21] B.Q. Thuat, "Research on extraction technology to improve yield and quality of oil from Gac aril (Momordica cochinchinensis Spreng L.)", Vietnam Journal of Science and Technology Vol. 48(1), 2010. Doi: https://doi.org/10.15625/0866- 708X/48/1/1089

[22] B. Rodriguez-Amaya, M. Kimura. HarvestPlus Handbook for Carotenoid Analysis, 2004.

[23] H.A. Oki, N. Thi, M.K. Ieu, N.K. Uze, K.T. Omisaka, “Carotenoid Pigments in Gac Fruit (Momordica cochinchinensis Spreng)”, Vol. 66(11), Pp. 2479- 2482, 2002.

[24] D.T.T. Nhung, P.N. Bung, N.T. Ha, T.K. Phong, "Changes in lycopene and beta carotene contents in aril and oil of Gac fruit during storage", Food Chemistry, Vol. 121(2), Pp. 326-331, 2010. 